\title{
SUICIDAL IDEATION IN PSORIASIS
}

\author{
MADHULIKA A. GUPTA, M.D., F.R.C.P. (C), NICHOLAS J. SCHORK, M.A.,
}

ADITYA K. GUPTA, M.D., F.R.C.P. (C), SUEANN KIRKBY, B.S.N., AND CHARLES N. ELLIS, M.D.

\begin{abstract}
Background. Psoriasis has been associated with depressive disease and case reports of completed suicide.
\end{abstract}

Methods. 217 consenting psoriasis patients completed the Carroll Rating Scale for Depression (CRSD), a 52 -item selfrated scale, with four of the items directly addressing wishes to be dead and suicidal ideation. The patients also self-rated the severity of their psoriasis.

Results. $9.7 \%$ of patients reported a wish to be dead, and $5.5 \%$ reported active suicidal ideation at the time of the study. The death wish and suicidal ideation were associated with higher depression scores $(\mathrm{P}<0.0001)$ and higher patient self-ratings of psoriasis severity $(P<0.05)$. Patient selfreports of psoriasis severity correlated directly with the overall depression scores $(r=0.39), P<0.0001)$.

Conclusions. The comorbidity between depressive symptoms, suicidal ideation, and psoriasis severity is in contrast with reports that severe depression and suicidal ideation are mainly a feature of life-threatening medical disorders such as malignancies. Our finding may have important implications in the management of psoriasis.

Int J Dermatol 1993; 32:188-190

Psoriasis has been associated with a range of psychiatric morbidity including depressive disease $\mathrm{e}^{1,2}$ and case reports of completed suicide. ${ }^{3} \mathrm{~A}$ wish to be dead and suicidal ideation often precede suicide attempts. In this study we have evaluated the prevalence of a wish to be dead and suicidal ideation among psoriasis patients, and examined the relationship of these thoughts to the severity of depression and subjective indices of psoriasis severity. To our knowledge, this is the first reported study that has systematically evaluated this important clinical feature of psoriasis.

\section{Materials and Methods}

Two hundred and seventeen consecutive consenting patients with psoriasis (79 outpatients and 138 inpatients), all

From the Departments of Psychiatry and Dermatology, University of Michigan Medical School, Ann Arbor, Michigan.

Address for correspondence: M.A. Gupta, M.D., Box 0704, CFOB, Department of Psychiatry, University of Michigan Hospitals, 1500 East Medical Center Drive, Ann Arbor, MI 48109-0704. attending the Department of Dermatology at the University of Michigan, completed the Carroll Rating Scale for Depression. This was completed in conjunction with a battery of other psychologic questionnaires as part of a large study of psychosocial factors in psoriasis.

The Carroll Rating Scale for Depression (CRSD) is a 52 item self-rated instrument, which is used to screen for the clinical depressive syndrome. ${ }^{4,5}$ The CRSD includes a measure of depressed mood along with other vegetative symptoms of depression such as change in sleep, sex drive, appetite, concentrating ability, and feelings of hopelessness and suicidal ideation. A global CRSD score of greater than 10 is used to screen for the presence of clinical depression. 4,5 Each of the 52 items in the CRSD are self-rated by the patient as "Yes" or "No." Four of the 52 items relate to wishes to be dead and suicidal ideation, and read as follows: "Dying is the best solution for me"; "I often wish I were dead"; "I feel that life is still worth living"; and, "I have been thinking about trying to kill myself."

In addition, the patients self-rated four separate indices of psoriasis severity including redness, scaling, plaque thickness, and a global severity rating. The patient self-ratings were carried out on a ten-point scale where a rating of "1" denoted "not at all" and a rating of "10" denoted "very markedly." The patient population represented a relatively heterogeneous group of both inpatients and outpatients, with the percentage body surface area affected by psoriasis ranging from less than $10 \%$ to over $90 \%$.

Statistical Analysis: Simple correlations were used to examine the relation between various indices of psoriasis severity and the global depression (CRSD) score. Two sample t-tests were used to compare the difference in the depression scores and the psoriasis severity ratings among the two groups of psoriasis patients, those with and without a death wish.

\section{RESULTS}

The patients (mean age \pm SD: $47.8 \pm 16.2$ years; 111 men and 106 women) had a mean depression or CRSD \pm SD score of $11.9 \pm 7.9$, and mean \pm SD psoriasis severity self-ratings (on the 10-point scale described above) as follows: redness $5.6 \pm 3.2$; scaling $4.8 \pm 3.0$; plaque thickness $5.1 \pm 2.6$; global severity $5.9 \pm 2.8$.

Table 1 summarizes the prevalence of items related to a death wish among the patients and the mean depression (CRSD) and psoriasis severity scores among the two groups of patients with and without a death wish. 
Table 1. Prevalence of Death Wish Among Psoriasis Patients

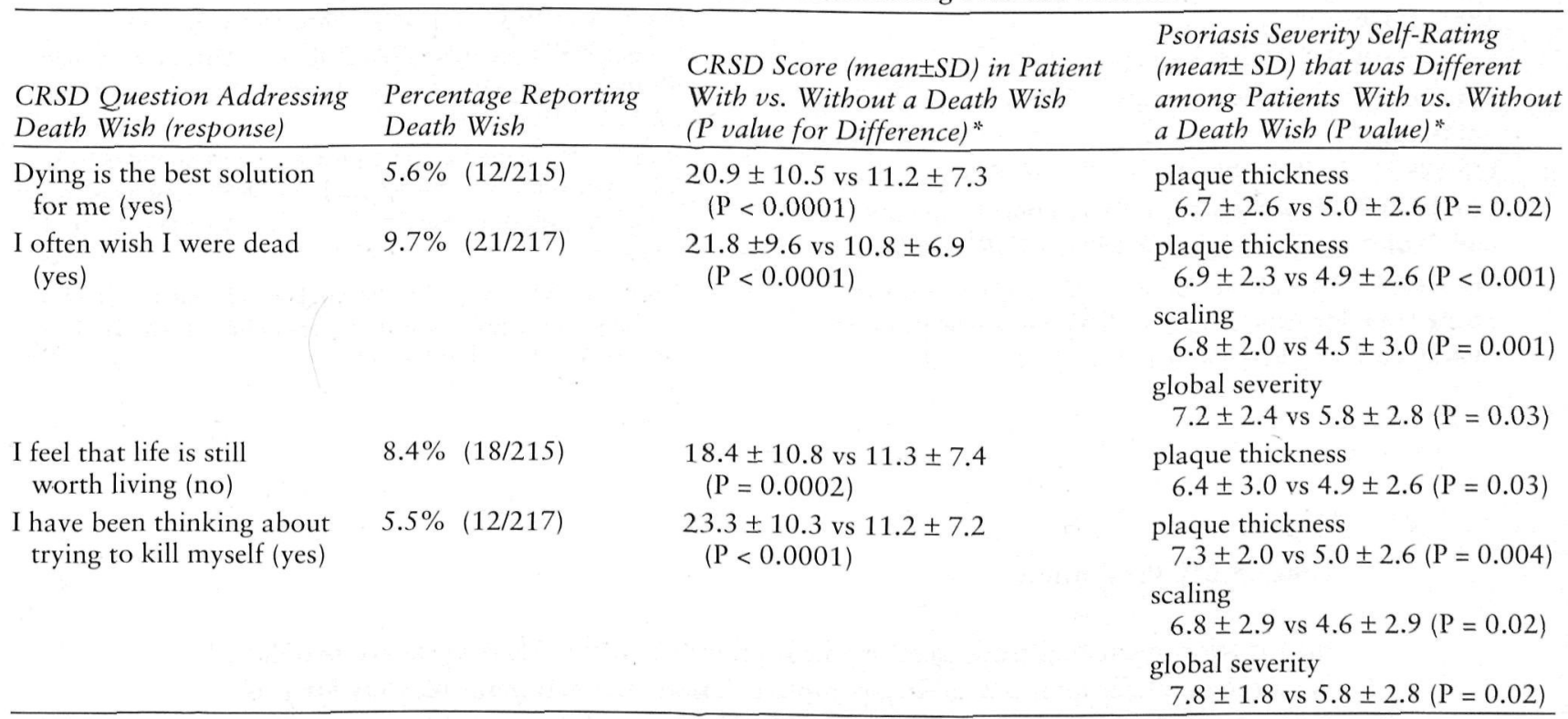

*Two sample $t$-test.

Age and sex did not differ significantly between the two groups.

Results of the correlation between severity of depression (i.e., mean CRSD score) and self-ratings of psoriasis were as follows: redness, $\mathrm{r}=0.12, \mathrm{P}=0.09$; scaling, $\mathrm{r}=0.25, \mathrm{P}=0.0002$; plaque thickness, $\mathrm{r}=0.24, \mathrm{P}$ $=0.0004$; global severity, $\mathrm{r}=0.39, \mathrm{P}<0.0001$. Age of the patient did not correlate significantly with indices of psoriasis severity.

\section{DISCUSSION}

Almost $10 \%$ of patients reported a wish to be dead, and $5.5 \%$ reported active suicidal ideation at the time of the study (Table 1). The presence of a death wish was associated with significantly higher depression (CRSD) scores and self-rated measures of psoriasis severity (Table 1 ). The significance of the comorbidity between depression and psoriasis is difficult to interpret, because the data in this study is from a one-time cross-sectional survey. It is possible that our patients were premorbidly depressed, and this predisposed them to developing more severe psoriasis. Alternately, having to cope with psoriasis could have resulted in a depressive reaction among the patients. The clinical significance of the correlations also have to be interpreted in light of our finding that, for example, the correlation coefficient ( $\mathbf{r}$ ) of 0.39 between depression and global severity indicates that depression accounted for only $15 \%$ of the variance in the global severity. As is to be expected, a majority of the variance in psoriasis severity was most likely determined by non-psychiatric factors.
The literature on depression in medical disorders ${ }^{6}$ has tended to focus upon life threatening illnesses such as malignancies, cardiovascular disease, and end-stage renal disease and essentially ignores non-malignant diseases of the skin. Generally, fatal and life-threatening medical disorders have been associated with severe depression, which is usually associated with suicidal ideation. ${ }^{6}$ To our knowledge, only one study has evaluated the presence of suicide risk among patients with a non-malignant skin disorder, i.e., Darier's disease associated with marked cosmetic disfigurement. ${ }^{7}$ In surveys of suicidal ideation among the general population, $7 \%{ }^{8}$ to $10 \%$ of patients wished that they were dead and life was not worth living at some time over the previous 1 year and over their lifetime ${ }^{9}$ respectively. A percentage of patients $\left(3.9 \%^{8}\right.$ to $\left.2.5 \%^{9}\right)$ reported having serious suicidal thoughts at some time over the previous 1 year ${ }^{8}$ and over their lifetime respectively. In comparison to these Canadian ${ }^{8}$ and British ${ }^{9}$ studies, $^{2}$ there was a higher point prevalence of suicidal ideation among our psoriasis patients. Future studies require a more demographically matched control population. Our findings are also in contrast with reports that severe depression and suicidal ideation are mainly a feature of life-threatening medical disorders. The clinician should be aware of the comorbidity between depressive symptoms, suicidal ideation, and psoriasis severity, as this can have important implications in the overall management of psoriasis.

\section{REFERENCES}

1. Gupta MA, Gupta AK, Kirkby S, et al. Pruritus in psoriasis, a prospective study of some psychiatric and dermatologic correlates. Arch Dermatol 1988; 124:1052-1057. 
2. Preston K. Depression and skin diseases. Med J Aust $1969 ; 1: 326-329$.

3. Sandborn III DE, Sandborn CJ, Cimbolic P, et al. Suicide and stress-related dermatoses. Dis Nerv Syst 1972; 33:391-394.

4. Carroll BJ, Feinberg M, Smouse PE, et al. The Carroll rating scale for depression: I. Development, reliability and validation. Br J Psychiatry 1981; 138:194-200.

5. Feinberg M, Carroll BJ, Smouse PE, et al. The Carroll rating scale for depression: III. Comparison with other instruments. Br J Psychiatry 1981; 138:205-209.
6. Rodin G, Voshart K. Depression in the medically ill: an overview. Am J Psychiatry 1986; 143:696-705.

7. Denicoff KD, Lehman ZA, Rubinow DR, et al. Suicidal ideation in Darier's disease. J Am Acad Dermatol 1990; 22:196-198.

8. Ramsay R, Bagley C. The prevalence of suicidal behaviors, attitudes and associated social experiences in an urban population. Suicide Life Threat Behav 1985; 15: 151-167.

9. Paykel E, Meyers J, Lindethal J, et al. Suicidal feelings in the general population: a prevalence study. Br J Psychiatry $1974 ; 124: 460-469$.

\section{Cold Injury Prevention}

Information regarding traditional medical practices of the Alaskan native peoples is scarce, haphazard and at best incomplete. There are two main reasons for this situation. First, in many cases native culture was assimilated and diluted by white influence so rapidly that ancient medical practices were lost before they could be recorded. Furthermore, medical therapeutics varied greatly between tribal groups. Unfortunately the vastness of the territory and the great distances separating their homeland allowed for thorough study of only a few of these tribes. Therefore, much of what is known of the health and healing practices of these people is derived from rather limited resources. Nevertheless, an overview of these medicinal practices provides a unique background for a discussion of contemporary cold injury concepts.

Obviously the preferred way to deal with cold injury was to avoid it altogether. Native Alaskans seemed to take a common sense approach to protecting themselves from the cold. Although there is no conclusive evidence for physiological acclimatization to environmental cold in man, circumpolar peoples certainly demonstrated superb habituation and accustomization to the arctic winters. In fact, some tribes were much more concerned with the dangers of unusually high temperatures, than with very low temperatures. A reasonable explanation may have been that fever was internal and of mysterious origin; whereas cold was external, identifiable and well within the realm of experience of Alaska natives.

Frostbite was apparently a common minor problem among Alaskan Indians, however serous freezing or hypothermia was extremely rare. Eskimos also had very little difficulty with hypothermia or frostbite. The hands very rarely became frozen, since when chilled, they were held inside a parka hood or placed against the flesh of the lower abdomen.

Undoubtedly native clothing played a large part in the prevention of cold injury. However, it has been difficult for anthropologists to precisely determine the aboriginal dress of Alaskan native peoples. Traditional ways of dress rapidly disappeared after contact with the white man. Whatever clothing was worn by Athapaskans was carefully kept dry to preserve insulative warmth. Overexertion and sweating were avoided during the winter months to prevent absorption of body moisture into clothing. If the garments did inadvertently become wet, they were quickly dried over a fire.

Eskimo footgear was evidently very effective as well, since frostbitten feet were also a rare occurrence. By employing a layering system of dress, Eskimos were able to avoid dampening their clothing during periods of heavy physical exertion. Interestingly, the layering method of winter dress has only recently become preferred among outdoor winter sports enthusiasts. From Foutch RG, Mills WJ. Treatment and prevention of cold injuries by ancient peoples indigenous to arctic and subarctic regions. Arctic Med Res 1988; 47(suppl 1):286-289. 
This document is a scanned copy of a printed document. No warranty is given about the accuracy of the copy. Users should refer to the original published version of the material. 